ARTICLE

\title{
Understanding drivers when investing for impact: an experimental study
}

\author{
Luisa De Amicis (10) 1, Silvia Binenti (1) 1,2, Felipe Maciel Cardoso (1) ${ }^{3 凶}$, Carlos Gracia-Lázaro (1) 3,4, \\ Ángel Sánchez ${ }^{3,5,6}$ \& Yamir Moreno (1) $3,4,7$
}

\begin{abstract}
In the last decade, a global interest in impact investing-whose goal is to generate social and environmental benefits alongside economic returns-has rapidly grown. In this context, this paper explores the socio-demographic characteristics of investors who choose impact investment options over traditional investments, and on the drivers promoting such choices. More specifically, the study consists of an experiment-based research in which 602 participants (non-experts and experts in the financial sector) took part in a multiplechoice game involving different investment scenarios and incentive conditions. The findings show that both expert investors and female participants are more likely to choose impact investment options and that the tendency to invest in social funds increases with age. Neither external and centrally planned incentives, such as fiscal incentives, nor the educational level of participants show a significant influence on investment choices. By contrast, information about the actual social impact achieved by funds plays a role in promoting socially oriented decisions. In this regard, visual aids appear to be an effective means of promoting impact investment. These findings may be of interest to policymakers, social campaigners and investment practitioners themselves when designing strategies for raising interest in impact investing or norms to strengthen a conducive and enabling environment for social entrepreneurship more broadly.
\end{abstract}

\footnotetext{
${ }^{1}$ PlusValue, London, UK. ${ }^{2}$ St. John's College, University of Cambridge, Cambridge, UK. ${ }^{3}$ Institute for Biocomputation and Physics of Complex Systems BIFI University of Zaragoza, Zaragoza, Spain. ${ }^{4}$ Departamento de Física Teórica, Facultad de Ciencias, Universidad de Zaragoza, Zaragoza, Spain. ${ }^{5}$ Grupo Interdisciplinar de Sistemas Complejos GISC, Departamento de Matemáticas, Universidad Carlos III deMadrid, Madrid, Spain. ${ }^{6}$ UC3M-BS Institute of Financial Big Data IFIBID, Universidad Carlos III de Madrid, Madrid, Spain. ${ }^{7}$ ISI Foundation, Turin, Italy. ${ }^{凶}$ email: fmacielcardoso@gmail.com
} 


\section{Introduction}

$\mathrm{n}$ recent years, impact investing has risen to prominence in a global business environment that is increasingly concerned, and at times even pressured, to take into account social and environmental issues. Impact investing is thus marking a new trend among traditional practitioners, institutions and policymakers worldwide, and the range of impact investment options and opportunities at global level has naturally grown in parallel to the expanding interest in social investment. The Global Impact Investing Network (GIIN, 2019) estimates that the sector has grown from $\$ 4.3$ billion in 2011 to $\$ 502$ billion in $2018^{1}$ and, at the upper end of the market, impact investing is estimated to reach as much as $\$ 1$ trillion in value by 2020 (Bowes, 2019).

In light of this new trend, a growing body of research emerged to define the theory and practice of social finance. The GIIN (2016) defines impact investments as a form of investment that is "made into companies, organisations, and funds with the intention to generate social and environmental impact alongside a financial return". According to this interpretation of the term and phenomenon-arguably the most accredited and quoted one-the two defining elements of impact investments are the expectation of financial returns on capital, or at minimum a return of capital, and intentionality, namely the intention of having a positive impact as a direct consequence of a deliberate action. Despite the centrality of expectations and intentionality, current research has mainly focused on impact assessment and measurement frameworks aimed at capturing the environmental and social returns generated by investments (Esteves et al., 2012; Epstein and Yuthas, 2017; Findler, 2019; Hervieux and Voltan, 2019; Jackson, 2013; Karytsas et al., 2020; OConnor and Labowitz, 2017; Portales, 2019; Serafeim et al., 2020; Tsotsotso, 2020). While such a focus is critically important to matters of effectiveness, accountability and transparency, it represents a debated and contested field that dominates and largely monopolise research on impact investments. Compared to other instances of socially responsible business practices that have been widely investigated through the lens of reputation/ brand building and consumption theories (McWilliams and Siegel, 2000; Lee, 2008; Campbell, 2007), little research has been conducted on the socio-demographic characteristics and the behavioural drivers pushing investors to choose impact funds over traditional investments.

Yet, if we are to make social finance a "standard practice", it is crucial to look at what might render impact-oriented funds a more appealing investment options and to whom-in this light, this study aims to contribute to this research gap through an experiment-based investigation. The value of exploring investors' behaviour and their decision-making process is two-fold. First, in the context of behavioural economics and game theory, such a focus can add significant value to existing research by shedding light on the nudging factors and determinants influencing the choices of economic actors (i.e., intrinsic value of the research focus). Second, behavioural insights can have implications for normative initiatives or incentive actions aimed at pushing the impact investing trend into the mainstream, such as awarenessraising campaigns, marketing strategies and policy-making (i.e., instrumental value of the research).

Within this wider scope of investigation and focus, the present experiment-based research aims to address the following questions:

RQ1 What is the effect of previous knowledge about impact investing? Do economic actors invest differently if they are already familiar with the concept of impact investing as opposed to those who have never heard of it?

RQ2 How do investors' preferences change depending on the way different investment instruments are proposed to them?
RQ3 How much financial return are investors willing to sacrifice for social impact, considering different risk factors?

RQ4 Do external factors affect the behaviour of economic actors (i.e., could incentives from the government change investors' behaviour)?

The experiment consists of a multiple-choice game envisaging different investment scenarios. According to their performance in an effort task at the beginning of the game, participants are given a budget to simulate investment decisions under different incentive circumstances while controlling for different variables, such as prior knowledge about impact investing. The experiment is directed at two different sample groups: non-experts, who are likely to have no prior knowledge on the concept of impact investing, and "experts", namely professionals working in the impact investing sector. As an incentive to elicit truthful behaviour, and at variance with traditional surveys, participants are economically rewarded according to the earnings they make through their investment decisions. Following the experiment, the data is analysed through logistic regressions. This approach was preferred over percentages as the regression analysis allowed to isolate the effect of each variable.

The research design allows to draw a number of conclusions that will be of interest for stakeholders and policy-makers aiming to promote impact investing. The study concludes that people operating in the sector (experts) and female participants tend to favour the impact investing option. Furthermore, the older people are, the more attracted to impact investing they appear to be. External factors such as fiscal incentives influence positively, although only marginally, the respondents' behaviour in choosing Impact Investing Funds (IIF) over Traditional Investing Funds (TIF). No clear correlation has been found between the participants' educational level and their disposition to invest for impact. Providing additional details or, more effectively, images on the social purpose and impact of the IIF has proved to be critical in substantially increasing the probability of opting for an IIF over a TIF, both for male and female participants. Furthermore, participants were less likely to choose the IIF option when this was associated with higher risk (for both male and female participants). Finally, when considering participants' prior knowledge on the topic, the difference between control groups was relatively small-yet, it appears that providing participants with key information on social finance (by showing them a video) had a positive impact with normative implications for current incentive structures, awareness campaigns and educational programmes about impact investing.

\section{Research design and methodology}

Sample description and experiment preliminaries. We designed an experimental set-up wherein subjects could interact individually with the experiment through a web landing page, supported by an application based on the oTree platform (Chen et al., 2016). Participants were given the opportunity to make individual decisions in their own time and environment, limiting the potential impact of endogenous biases. Two pools of participants were selected for this experiment. The first subject group consisted of a non-probability sampling of 541 individuals who were likely to have no previous knowledge on the concept of impact investing. This non-discriminatory group presented great practical advantages without constituting an inferential risk on the research outcomes, as shown by and adopted in several other experiment-based researches (Druckman and Kam, 2011). The second subject group consisted of 61 experts and practitioners in the field of impact investing-they were recruited through the 
researchers' wide professional network in the world of social finance and thanks to a referral sampling system.

At the beginning of the experiment, participants were asked to fill in a standard demographic questionnaire. Out of a sample of 602 participants, 367 were female $(61 \%, 341$ non-experts and 26 experts) and 235 were male $(39 \%, 200$ non-experts and 35 experts). Tables 1 and 2 provide information on the participants' level of formal education and country of residence, respectively; Figure 1 shows the age distribution and gender across the two sample groups. Following the demographic questionnaire, subjects were directly asked whether they held any prior knowledge on "impact investment". In case of a positive answer, the participant could proceed to the game; in case of a negative answer, with a $50 \%$ chance, participants were shown a 2 -min video tutorial briefly introducing them to the concept and practice of impact investment (for video see MBA, 2017)-if shown, participants could proceed to the next step of the experiment only after having watched the video until the end. In this way, we secured a diverse sample in which prior knowledge

\section{Table 1 Level of formal education of non-experts (two} leftmost columns) and experts (two rightmost columns).

\begin{tabular}{|c|c|c|c|c|}
\hline & \multicolumn{2}{|c|}{ Non-experts } & \multicolumn{2}{|l|}{ Experts } \\
\hline & Female & Male & Female & Male \\
\hline 3-year bachelor & 33 & 14 & 1 & 1 \\
\hline 4-year bachelor & 79 & 45 & 2 & 4 \\
\hline 5-year bachelor & 59 & 24 & 2 & 3 \\
\hline Lower secondary education & 15 & 10 & 0 & 0 \\
\hline Master (1 year) & 35 & 20 & 4 & 7 \\
\hline Master (2 years) & 31 & 15 & 11 & 11 \\
\hline Other (non-listed) & 20 & 7 & 2 & 0 \\
\hline Ph.D. & 7 & 4 & 3 & 8 \\
\hline $\begin{array}{l}\text { Post-secondary, non-tertiary } \\
\text { education }\end{array}$ & 18 & 20 & 0 & 0 \\
\hline Short-cycle, tertiary education & 21 & 18 & 0 & 1 \\
\hline Upper secondary education & 23 & 23 & 1 & 0 \\
\hline Total & 341 & 200 & 26 & 35 \\
\hline
\end{tabular}

on impact investing could be factored in and controlled for. This is summarised in Table 3, showing the answers of non-experts.

Effort task. The core part of the experiment consisted of an investment game in which individuals were asked to make scenario-sensitive investment decisions generating different financial returns and impact outcomes, including no impact at all. In order to simulate the way investors have a real stake in their

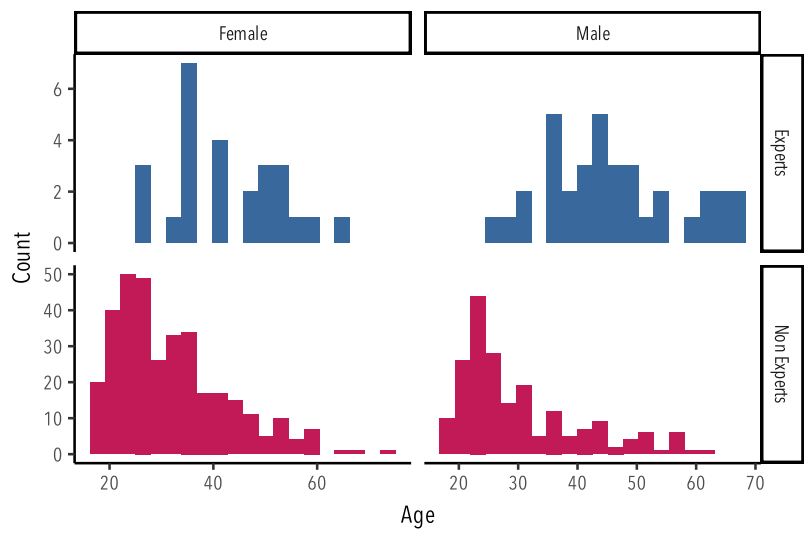

Fig. 1 Age distributions of the participants in the experiment. Top left: female experts. Top right: male experts. Bottom left: female non-experts. Bottom right: male non-experts.

Table 3 Non-experts prior knowledge about impact investing.

\begin{tabular}{|lll} 
& Non-experts & \\
\cline { 2 - 3 } & Female & Male \\
\hline Prior knowledge & 66 & 45 \\
No prior knowledge-did see the video & 129 & 74 \\
No prior knowledge-did not see the video & 146 & 81 \\
\hline
\end{tabular}

Table 2 Country of residence of participants.

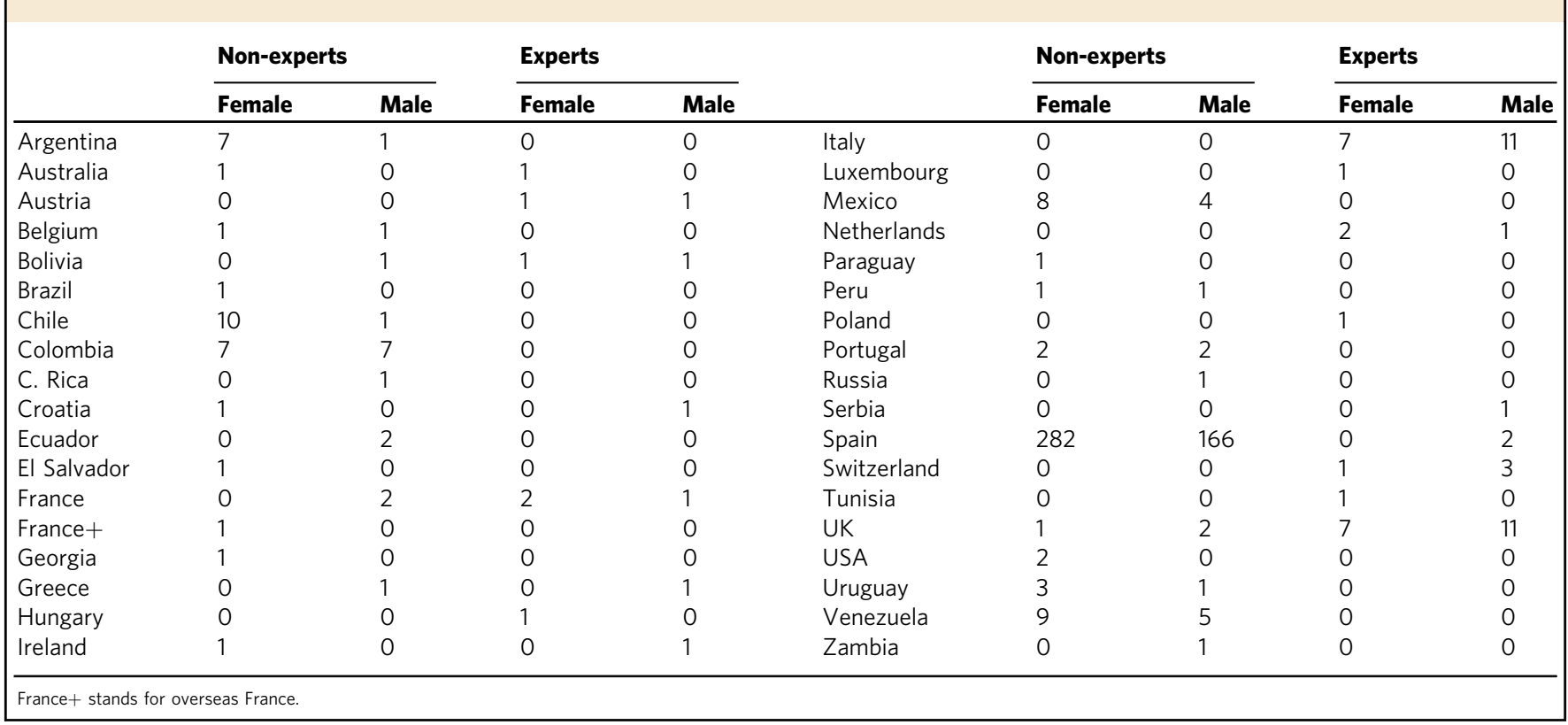


investment decisions by relying on their own financial capital, the experiment began with a simple effort task, in which the subject was asked to count the number of "ones" displayed in a sequence of $1 \mathrm{~s}$ and 0 s (see Fig. 2). Participants were then assigned a budget as a function of how well they performed in the effort task-this budget represents the "capital" they could invest in each of the scenarios proposed during the game. Most participants obtained the maximum score in the effort task, and hence the largest endowment/capital for the investment game. More specifically, $90.3 \%$ of experts and $94.4 \%$ of non-experts indicated the correct solution in the effort task.

As already mentioned, contrary to fixed or randomised initial endowments, the psychological implications of performing an effort task help strengthening the external validity of the game as participants are expected to feel more 'attached' to the money they actually earn and invest-this more accurately resembles real-life conditions (Argyle and Furnham, 2013). Moreover, by the rules of the game, subjects were made aware that, thanks to a lucky draw selecting about $10 \%$ of participants, their earnings for each investment decision could be turned into real money. At the end of every question, participants were provided the following reminder to ensure they paid equal attention to all questions: "After you have answered all the questions, one question will be randomly selected and that will be the question used to calculate your earnings.” A similar setup was used by Gneezy et al. (2014) to study the effect of overheads on the donations to charities. In this way, the lottery not only helped recruit more participants (this applies specifically to non-experts, who do not necessarily hold a particular interest in the field of social finance and hence in outcomes of the research), but also helped instil a realistic sense of 'profitability' that would normally characterise personal investments. As a result, in spite of the small 'capital' participants were given to invest in the experiment, the line between the game and real-life could be partially blurred given that participants' decisions did actually have an impact on their pockets at the end of the game (Charness et al., 2016).

Questions. The core part of the game consisted of eight different investment scenarios comprising simple multiple-choice questions. In each of these proposed scenarios, subjects were asked to choose between traditional investment options and impact fund options. Each of these binary choices probed into different aspects of our research questions.

- (Q1) Simple "traditional versus impact" investment scenario: Participants were asked to choose between a TIF yielding a

\begin{tabular}{|c|}
\hline 01010001000001100110 \\
\hline 10011010011011000010 \\
\hline 01010100100100001111 \\
\hline 00001011001100001001 \\
\hline 10110011000110000110 \\
\hline 10000011011001101110 \\
\hline 010010 \\
\hline
\end{tabular}

Type the number of ones:

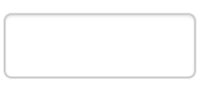

Fig. 2 Participants' budget is determined by an effort task. Screenshot of the effort task proposed to participants. They had to count and type the number of 'ones' shown in the figure.
$5 \%$ return, or an IIF yielding a $4 \%$ return and helping provide access to clean water in developing countries.

- (Q2) "Traditional versus impact" investment scenario with different social return options: Participants were proposed the same scenario as (Q1) with a fixed TIF yielding a $5 \%$ return or an IIF with a $4 \%, 3 \%, 2 \%$ or $1 \%$ return. This scenario was aimed at understanding how much financial return investors are willing to sacrifice for social impact as they are progressively proposed different return options.

- (Q3) and (Q4) "Traditional versus impact" investment scenarios with additional details on social impact and with/ without different social return options: These questions were set up in the same way as (Q1) and (Q2), respectively; however, participants were also provided with more information on the actual impact achieved by the IIF, whereby drawing a more concrete picture in the mind of the investor on the impact that could be achieved.

- (Q5) and (Q6) "Traditional versus impact" investment scenario with a risk factor and with/without different social return options: Following the logic of the previous questions, (Q5) and (Q6) investigated how decisions between TIF and IIF are affected by the risk factor of having no returns at all, with the traditional investment option being more probable to generate economic returns (and no social impact) than the IIF ( $90 \%$ chance of yielding a return versus $80 \%$ ).

- (Q7) “Traditional versus impact" investment scenario with a fiscal benefit: In this scenario, participants were asked to choose between a TIF yielding a $5 \%$ return or an IIF yielding a $4 \%$ with a tax deduction of $20 \%$ of the invested amount.

- (Q8) "Traditional versus impact" investment scenario with additional details on social impact and visual aid: Finally, in this scenario, participants were presented with a more detailed description of the social impact generated by the IIF supported by an illustration as well as additional geographical coordinates. The scenario was presented as follows:

According to WaterAid, Papua New Guinea has the world's worst access to clean water, with $60 \%$ of the population living without a safe water supply. For the poorest population section, getting ill or even dying from drinking dirty water is normal.

This question, along the lines of (Q3) and (Q4), was aimed at exploring the relationship between a potential empathy factor given by an additional visual incentive. The photo (shown in Fig. S12 of the SI) was intentionally chosen as it does not depict the beneficiary of the impact investment as a victim (the community in the photo actively reacts to a problem-i.e. access to clean water-rather than passively bearing the consequences), while picturing human figures that can more easily trigger empathy or a fellow-feeling of solidarity (Burt and Strongman, 2005).

In summary, each of the questions presented above has been designed within a given research framing as summarised in Table 4. The full description of the experiment is given in the

Table 4 Summary of framings proposed to participants and its corresponding research question.

\begin{tabular}{|lll} 
Framing & Question & Research question \\
\hline TIF vs. IIF & Q1 \& Q2 & RQ1 \\
Impact description & Q3 \& Q4 & RQ2 \\
Risk factor & Q5 \& Q6 & RQ3 \\
Tax deduction & Q7 & RQ4 \\
Visual aid & Q8 & RQ2 \\
\hline
\end{tabular}


Table 5 Framing of questions.

\begin{tabular}{ll} 
& Model 1 \\
\hline Intercept & $\mathbf{1 . 7 5}(0.11)^{\star \star \star}$ \\
Impact description & $\mathbf{0 . 4 3}(0.18)^{\star}$ \\
Risk factor & $\mathbf{0 . 6 7}(0.15)^{\star \star \star}$ \\
Tax deduction & $-0.29(0.16)$ \\
Visual aid & $\mathbf{0 . 6 3}(0.19)^{\star \star \star}$ \\
AIC & 2520.36 \\
BIC & 2550.41 \\
Log likelihood & -1255.18 \\
Deviance & 2510.36 \\
No. of obs. & 3010 \\
\hline Log-odds ratio of coefficients obtained by logistic regression. Questions coefficients correspond \\
to their difference in effect with respect to the intercept (i.e., the reference value). The intercept \\
corresponds to the log-odds ratio which chose the IIF over the TIF (Question 1), computed over \\
all the participants. Observations correspond to all participants' responses to the two-choice \\
questions (Q1, Q3, Q5, Q7, Q8). Values in bold correspond to statistically significant \\
coefficients. \\
${ }^{\star} p<0.05,{ }^{\star \star \star} p<0.001$
\end{tabular}

Supplementary Information (1) appendix reporting the instructions given to the participants.

\section{Results}

To analyse the impact of each control factor on IIF investments, we performed a series of regressions (Tables 5-7). Table 5 shows the effect of each question framing. Here, the intercept (i.e., the reference value) represents the willingness to invest in IIFs over TIFs with no additional framing. The difference between IIFs and TIFs decisions is explicitly addressed by Question $1-85.2 \%$ of the participants chose the IIF over TIF. The rest of the coefficients, namely impact description, risk factor, tax deduction, and visual aid, correspond to the respective effects of each framing, more explicitly their difference in effect with respect to the intercept term. Let us begin by the results summarised on Table 5. As it can be observed, there is a positive effect of the impact description on the IIF $(p<0.05)$, and this effect is higher and more significant $(p<0.001)$ when a visual aid is added to the information provided to participants - that is adding a picture of the people helped by the impact investment (Question 8). This visual aid makes people more likely to choose the IIF option. On the other hand, people are less likely to choose IIF option when this is associated with a higher risk $(p<0.001)$. Regarding tax incentives, deductions were not found to have a significant effect on the preferability of impact investing options.

Regarding the outcome of proposing different return options on impact investing, Table 6 shows the results of three different logistic regressions, each column corresponding to a different regression analysis. The first column (TIF vs. IIF) shows the results for the simplest case without additional information (questions Q1 and Q2). The second column corresponds to the scenario in which participants were provided with additional details on their social impact (Q3, Q4). The third column refers to scenarios where a risk factor was introduced, with TIF options being more probable to generate returns than IIF options (Q5, Q6). Significant negative Delta coefficients indicate that, if IIF provides lower returns than TIF, the higher the difference in returns, the lower the investments in IIFs $(p<0.001)$. This effect is robust against information and risk framing (both $p<0.001$ ).

The results for the impact of the demographics variables on IIF investments are shown in Table 7 . Here, each column corresponds to a different regression analysis, namely simpler scenarios without additional information (column TIF vs. IIFquestions Q1, Q2); scenarios with additional details on social impact (impact description-Q3, Q4); scenarions with higher risk
Table 6 Framing of multiple questions and fund profitability.

\begin{tabular}{|c|c|c|c|}
\hline & TIF vs. IIF & $\begin{array}{l}\text { Impact } \\
\text { description }\end{array}$ & Risk factor \\
\hline Intercept & $1.05(0.02)^{\star \star \star}$ & $1.08(0.02)^{\star \star \star}$ & $\mathbf{0 . 9 1}(0.02)^{\star \star \star}$ \\
\hline $\begin{array}{l}\text { Multiple } \\
\text { question }\end{array}$ & $-0.03(0.02)$ & $-0.01(0.02)$ & $0.04(0.02)$ \\
\hline Delta & $-\mathbf{0 . 2 0}(0.01)^{\star \star \star}$ & $-\mathbf{0 . 1 9}(0.01)^{\star \star \star}$ & $-\mathbf{0 . 1 6}(0.01)^{\star \star \star}$ \\
\hline AIC & 3481.80 & 3270.87 & 3843.07 \\
\hline $\mathrm{BIC}$ & 3505.83 & 3294.91 & 3867.11 \\
\hline $\begin{array}{l}\text { Log } \\
\text { likelihood }\end{array}$ & -736.90 & -1631.44 & -1917.53 \\
\hline Deviance & 558.86 & 521.04 & 630.13 \\
\hline No. of obs. & 3010 & 3010 & 3010 \\
\hline \multicolumn{4}{|c|}{$\begin{array}{l}\text { Log-odds ratio of coefficients obtained by logistic regression. Each column corresponds to a } \\
\text { different regression analysis: TIF vs. III (Q1 and Q2), impact description (Q3 and Q4), and risk } \\
\text { factor ( Q5 and Q6). The intercept corresponds to the log-odds ratio which chose the IIIF over the } \\
\text { TIF (Q1, Q3, Q5). Multiple question coefficients correspond to the difference in effect when } \\
\text { proposing different options (Q2, Q4, Q6) with respect to the intercept (Q1, Q3, Q5, } \\
\text { respectively). Delta coefficients account for effect IIFs return (Q2, Q4, Q6), i.e., they refer to the } \\
\text { return differences between TIF and IIF. Observations correspond to all participants' responses to } \\
\text { the two-choice questions and their corresponding multiple question (Q1 and Q2, Q3 and Q4, Q5 } \\
\text { and Q6). Values in bold correspond to statistically significant coefficients. } \\
\text { at* } p<0.001 \text {. }\end{array}$} \\
\hline
\end{tabular}

associated with IIF (risk factors-Q5, Q6); scenarios with fiscal benefit associated to the IIF (tax deduction-Q7); and scenarios with visual aid together with additional information on social impact (visual aid-Q8). The variables considered in this study are the following: gender; expertise (i.e., belonging or not to the group of experts); age, educational level, prior knowledge on impact investing (based on the way participants answered to the question on whether they held any knowledge on impact investment); display of video on impact investment (50\% among those without previous knowledge); and Delta (return differences between TIF and IIF).

Intercept coefficients show that participants are more likely to choose the IIF option, except, surprisingly, when this is associated with a fiscal benefit. In this scenario, we do not observe a significant gender difference, while being an expert appears to make a larger difference. Conversely, experts do not behave differently from the rest of participants when either risk or visual aid is taken into account. Age also affects responses distinctively in each question, as we discuss further in the next paragraphs.

The first column of Table 7 shows that: (i) women are more likely to invest in an IIF than men $(p<0.001)$, (ii) experts are more likely to invest in an IIF than non-experts $(p<0.001)$, and (iii) the willingness to invest in IIF increases with age $(p<0.001)$. On the other hand, the education level does not make a substantial difference in explaining the behaviour of investors. Furthermore, although previous knowledge on impact investing (according to the self-assessment of participants) does not influence the investment decision, the informative video played a positive role: participants who were shown a tutorial video on impact investing displayed a higher tendency to invest in IIF than those who did not watch it $(p<0.001)$.

When additional information on the actual impact achieved by the IIF was given to participants (second column of Table 7): (i) gender differences persist, with women being more likely to invest in IIFs than men $(p<0.001)$, (ii) experts are also more likely to invest in IIFs than non-experts $(p<0.001)$. Conversely, neither age nor education has a significant influence on IIF investment choices. Note that, although without additional information on social impact IIF investments increase with age (first column regression), this determinant disappears when additional information is provided (second column).

The effects of associating a higher risk with the IIF option $(20 \%$ chance of not yielding a return with IIF versus a $10 \%$ chance with 
Table 7 Demographic variables impact.

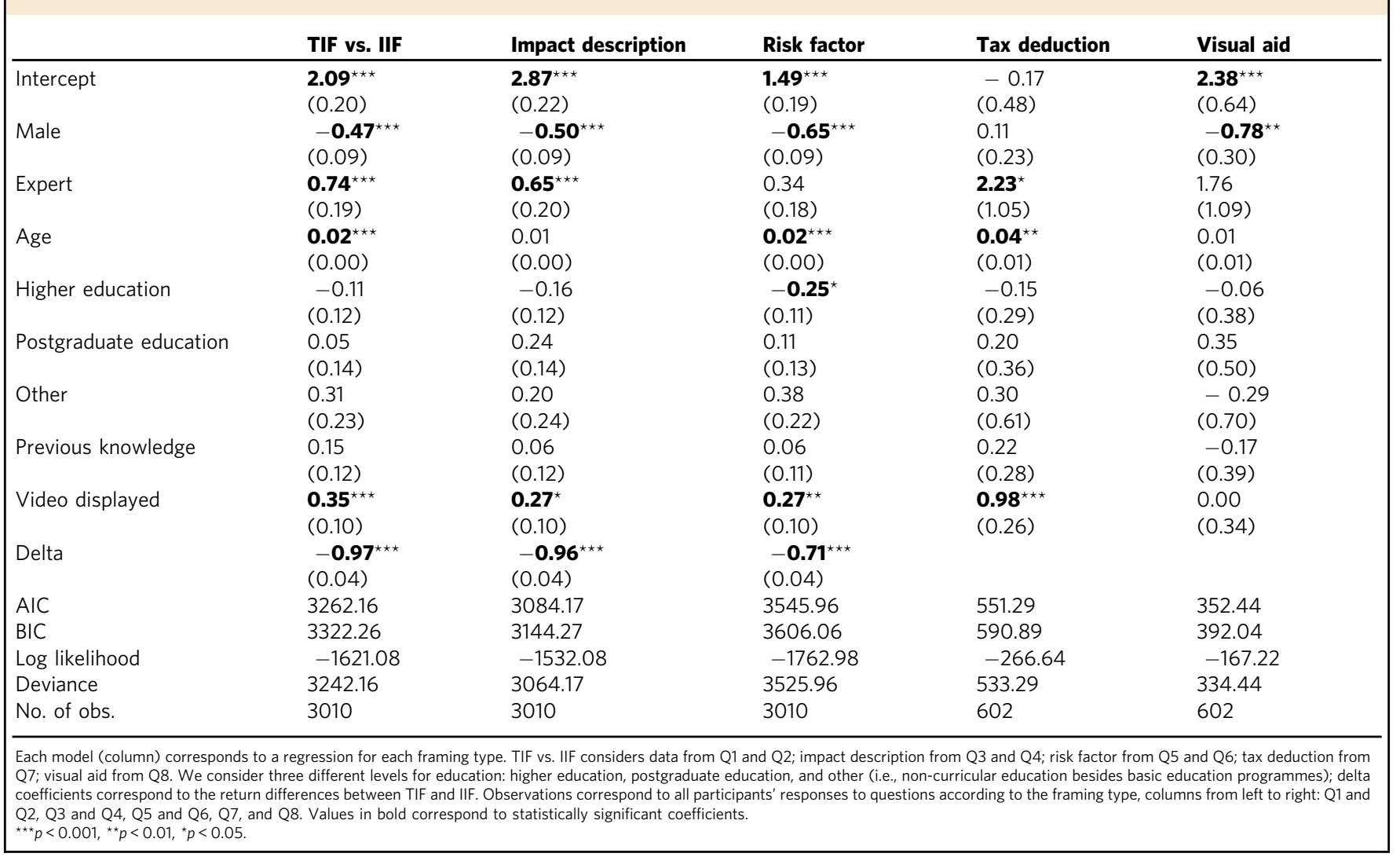

TIF) are shown on the third column of Table 7. It is shown that: (i) women are more likely to invest in higher risk IIF options than men $(p<0.001)$, (ii) opting for higher risk IIF increases with age $(p<0.001)$. On the other hand, when a higher risk is associated with the IIF, the higher tendency of experts to invest in IIFs vanishes.

Regarding tax deductions (fourth column of Table 7), surprisingly, a significant effect of tax deductions on the impact investing option was not found, except for experts and older subjects, who display a positive response to tax benefits. It is observed that, when a tax incentive is included in the scenario, experts $(p<0.05)$ and older subjects $(p<0.01)$ show a higher tendency to invest in IIFs. As in previous cases, although prior knowledge on impact investing does not show a significant influence on impact investing choices, participants who watched the informative video showed a higher tendency to invest in IIFs than those who did not see it $(p<0.001)$. This tendency is stronger when a tax deduction is included.

Finally, regarding the effect of an additional visual incentive, the fourth column of Table 7 shows the logistic regression for the scenario in which additional details on social impact supported by an image were shown to participants. As explained before, the visual aid increases the likelihood of opting for IIFs. In this scenario, gender is the only demographic variable that plays a significant role in the willingness to invest in IIFs-women showed were more likely to opt for IIFs over TIFs $(p<0.01)$. Neither expertise, age, education level, prior knowledge showed a significant influence on investment choices. Although women display a higher probability to opt for IIFs than men in the presence of a visual incentive, it cannot be stated that visual aids affect more women than men, since the difference in its influence is not significant according to logistic regression.

\section{Discussion}

Our results indicate that in most scenarios experts are more likely than non-experts to choose the impact investment option. This does not really come as a surprise: it is likely that experts entered the impact investing field driven by personal principles and moral considerations (Buttle, 2007; Carter and Huby, 2005), as working in the world of social finance may already reflect personal compromises between a less lucrative career and an ethical professional path (Lewis, 2002; Wins and Zwergel, 2015).

Our findings show that older people have a higher tendency to choose impact investment options than younger people. This is somewhat surprising given the current momentum of narratives such as "Millennials Will Bring Impact Investing Mainstream" (Emerson and Norcott, 2016), whereby young generations are expected to shift large capitals towards social causes, as well as prioritising socially meaningful careers and thus focus on social entrepreneurship (Novak et al., 2018; Stecker, 2014). Nevertheless, some studies have also shown that senior citizens are more prone to contribute to the common good (Molina et al., 2019), due to their willingness to leave a positive legacy behind. The explanation for such a result may be that the younger generations are interested in impact investment but do not have enough expertise or do not feel confident enough to take part in it. Indeed, the Financial Times (2018) reports that "while 64\% of the younger generation Credit Suisse surveyed were interested in impact investing, only $24 \%$ had actually invested". Numbers even decrease when looking at high net worth families. A research from Morgan Stanley (Stanley, 2014) shows that only 4\% of Next Gen family members consider themselves fully active participants spending "a great deal" of time engaged in impact investing, although the majority (60\%) of Next Gens consider "important" 
to use their family's wealth to make a positive social or environmental impact.

For almost all the questions, we can observe that women are also more willing to choose an IIF than men, except for the tax deduction question. This is well in line with the abundant literature on philanthropy and charity-giving that shows that women are more likely to engage in altruistic behaviour (Gunstone and Gavin, 2017; Wiepking and Bekkers, 2012). Even when a risk factor is introduced, more women prefer an IIF compared to male participants despite they are generally considered to exhibit a risk-averse behaviour. The tendency of women to prefer an IIF over a TIF is in line with existing research from the industry. Stephanie Luedke of Citi Investment Management, who works on the front lines of asset allocation, confirmed in a recent interview on Forbes (Doerr, 2018) that " $90 \%$ of women surveyed have indicated that they want to invest at least a portion of their wealth in a manner that aligns with their values". On the top of that, women are becoming wealthier, thanks to a more genderequal intergenerational transfer of wealth (Brown, 2019), and are proving to have entered a traditionally "male" environment as capable investors, as showed in a research from Fidelity in which women tended to outperform men in generating a return on their investments (Ficher, 2017).

When considering participants' prior knowledge on the topic, leaving expertise on the side, the difference between control groups is not significant. Yet, the experiment reveals that showing the video had a positive impact in prompting socially oriented decisions, whereby signalling a wider scope for promoting and raising awareness about impact investing. This is confirmed by our logistic regressions and represents one of the most important findings of our research in line with recent studies on the same topic (Novak et al., 2018). Public administration bodies and civil society organisations have already started to put efforts in raising awareness about impact investment. Organisations such as Big Society Capital, the social investment "wholesaler" set up in 2012 by David Cameron together with his Big Society agenda, or the Social Impact Agenda promoted by the Portuguese Government are an example of this. International political bodies, such as the European Union, did not adopt a "wait and see" approach; on the contrary, they took significant, active steps forward, such as the creation of the Expert Group on Social Entrepreneurship (GECES) in 2011 and the consequent report in 2016-"Social Enterprises and Social Economy going forward" (GECES, 2016) advocating for a greater visibility and enhanced understanding of social enterprises and impact investments. This kind of initiatives, however, generated mixed results; more needs to be done not only by coordinating efforts between governments and international institutions but also by encouraging inter-sectorial collaborations between researchers, the private sector and practitioners from the social economy and the social enterprise world, who could work together to gather stronger evidence on the added value of impact investment and better communicate their main results through institutional channels. In this regard, media outlets are currently missing an opportunity, especially in light of the positive general attitude towards the topic in public narratives (Novak et al., 2018). Furthermore, impact investing is not currently part of the curriculum of finance degrees and is not part of the formal training of a financier or corporate investor. Top universities are taking new steps in making innovative finance part of the mainstream and are increasingly engaged in the impact investing debate, knowledge-sharing and training. For instance, the Said Business School at the University of Oxford has recently launched a programme entitled "Oxford Impact Investing Programme: Build your investment skills to deliver maximum social return", directed at professionals and businesses that aim to enter the field -this integrates the work already undertook by the Skoll Centre for Social Entrepreneurship. In the same way, the Cambridge Institute for Sustainability Leadership (CISL) greatly focuses on sustainable business and leadership. Yet, these standard university degrees hardly cover impact investing. As a result, whilst universities are increasingly treating topics related to management and innovation for social good, there is still a long way to go in shifting the way we approach mainstream financial training and education, which could be a great starting point to radically change mainstream finance.

Another reflection point is about tax incentives, usually seen as a strong market builder. In our experiment, the tax incentive is the only case in which gender does not play a significant role, and both men and women do not see it as an incentive. This was a somewhat surprising, key finding of our research. As a matter of fact, despite what academic evidence suggests and our experiment confirms, public bodies still put a great emphasis on the tax benefits of giving. The UK Government, for instance, has introduced the social investment tax relief (SITR) scheme in 2014yet, the results have not been as positive as expected. In 2016-17, 25 social enterprises received new investments through the SITR scheme and $€ 1.8$ million of funds were raised. Since SITR was launched in 2014-15, 50 social enterprises raised funds of $€ 5.1$ million through the scheme (HMRC, 2018). These figures are far from the 300,000 social enterprises and charities that could potentially benefit from SITR, according to Big Society Capital (BSC, 2019). What is causing such a big difference? In a recent call for evidence launched by the British Government, organisations advocated for several changes suggesting that such incentives were not fit for purpose (Floyd, 2019). In this regard, our study confirms that tax incentives are not a game changer for people who are not experts in the field. One may wonder whether the problem lies in the design of incentive schemes or in the fact that tax incentives themselves are simply not a major determinant of investors' decisions. Other countries have launched similar tax incentive schemes in the past (i.e. France) and others (i.e., Italy) have just followed. In a few years from now, it would be interesting to see the impact of these recently implemented incentives and run further research to understand whether fiscal incentives can still be considered as a main driver for investors' behaviour or are just a nice add-on impacting the decision of 'only' a few.

The experiment also brought about the lingering scepticism about impact investing. Indeed, impact investing is still perceived by some as a suspicious hybrid where money-driven actors, philanthropists and practitioners (i.e., social entrepreneurs) are culturally polarised and still struggle to speak the same language (Novak et al., 2018). By way of example, one of the participantsand more specifically a participant from the expert poolreported feeling "almost angry" at the built-in reward mechanism of the game. He contested not feeling included in the scope of the experiment, which according to the participant implicitly assumed that people can only be incentivised by money; consequently, in this view, the experiment was meant for profitoriented "venture capitalists" only. While the design of the game was merely aimed at resembling real-life circumstances, we did not predict that offering a reward could have triggered negative reactions. In the same way, another expert participant never claimed the prize, thus showing his 'pure' willingness to engage in the debate and lack of responsiveness to monetary incentives.

\section{Conclusions}

Impact investing aims to generate social and environmental impact alongside a financial return. In this paper, we have run an experiment with 602 participants to understand what 'makes' impact investors and what are the drivers for their decisions. We apply logistic regression analysis on the acquired data-set. One of 
the main weaknesses of the study is the sample limitation for experts. However, we must note that the process of finding experts and get them to run the experiment requires considerable resources. There is not such a thing like a pre-defined available data-set for this, and therefore having access to experts and ensuring their participation to the experiment is a challenge in itself, also due to their time limitation.

The main contribution of this paper is the domain insight: our study shows that participants are generally favourable to invest in IIF, especially if they are women, older people, or individuals who were already familiar with the impact investing field (i.e., "experts"). With reference to this last point, while prior experience in the field has an impact on choices (RQ1), there was no significant difference between non-experts who reported some or no previous knowledge on impact investing. This might lead to two competing explanations: (i) non-experts who declared to have some knowledge on the field knew about it only vaguely; (ii) simply knowing about impact investing is not enough, and prior experience rather than mere knowledge is a more significant determinant of choices.

Surprisingly, external incentives such as tax breaks do not appear to be a game-changer (RQ4), and future research might determine when and why they might affect investors' decisions. On the other hand, when participants are informed of the risks attached to their investment, the likelihood to invest in an IIF decreases (RQ3), but it increases when more information about the impact of their investment is made available (RQ2). Particularly, we have seen that visual aids further increase the investors' willingness to choose an IIF across all categories analysed in this paper. We note that additional efforts should be made in raising awareness about impact investment, especially by policymakers and media outlets. Inter-sectorial collaboration between the public, private and third sector and academia (quadruple helix) should be encouraged, as well as the introduction of impact investing in the curriculum in financial training and education.

Future researches could benefit from a broader dataset. Tax incentives deserve special attention and researchers could focus on those countries that have already designed and implemented policies on this topic. An interesting twist to the research could be investigating how behaviour changes if the choice of the participants is made public, as an interest in reputation-building and positive self-branding may significantly drive people's choices.

\section{Acknowledgements}

We acknowledge partial support from the FET Proactive Project Distributed Global Financial Systems for Society (DOLFINS) (contract no. 640772). FMC, CG-L, and YM acknowledge partial support from Government of Aragón (Spain) and FEDER funds (UE) through grant E36-17R to FENOL, and from MINECO and FEDER funds (Spain/UE) through grant FIS2017-87519-P. YM also acknowledges partial support from Intesa Sanpaolo Innovation Center. AS acknowledges partial support from the Ministerio de Economía y Competitividad/FEDER (Spain/UE) through grant no. FIS2015-64349-P (VARIANCE) and from Ministerio de Ciencia, Innovación y Universidades/FEDER (Spain/UE) through grant PGC2018-098186-B-I00 (BASIC). The funders had no role in study design, data collection, and analysis, decision to publish, or preparation of the manuscript.

\section{Data availability}

The dataset concerning non-experts is available at Maciel Cardoso (2019). To ensure the anonymity of experts participants, their data will not be publicly available but can be obtained from the corresponding author on reasonable request.
Received: 13 November 2019; Accepted: 26 March 2020; Published online: 06 May 2020

\section{Notes}

1 The estimate is based on the responses provided by 266 leading impact investing organisations from around the world, managing collectively $\$ 239$ billion.

\section{References}

Argyle M, Furnham A. The psychology of money. Routledge (2013).

Bowes M (2019) Future trends in impact investing. https://www.ampcapital.com/ au/en/insights-hub/articles/2019/may/future-trends-in-impact-investing. Accessed 2 Sept 2019

Brown A (2019) Six reasons why women are shaking up impact investing. https:// www.triplepundit.com/story/2019/six-reasons-why-women-are-shakingimpact-investing/82571/. Accessed 2 Sept 2019

BSC (2019) Social investment tax relief critical for social enterprises and charities, argues big society capital. https:/www.bigsocietycapital.com/latest/type/ news/social-investment-tax-relief-critical-social-enterprises-and-charities. Accessed 2 Sept 2019

Burt CDB, Strongman K (2005) Use of images in charity advertising: improving donations and compliance rates. Int J Organ Behav 8:571-580

Buttle M (2007) I am not in it for the money: constructing and mediating ethical reconnections in UK social banking. Geoforum 38:1076-1088

Campbell JL (2007) Why would corporations behave in socially responsible ways? An institutional theory of corporate social responsibility. Acad Manag Rev 32:946-967

Carter N, Huby M (2005) Ecological citizenship and ethical investment. Environ Political 14:255-272

Charness G, Gneezy U, Halladay B (2016) Experimental methods: pay one or pay all. J Econ Behav Organ 131:141-150

Chen DL, Schonger M, Wickens C (2016) oTree-an open-source platform for laboratory, online, and field experiments. J Behav Exp Financ 9:88-97

Doerr P (2018) Changing the status quo: how women are leading the charge on impact investing. https://www.forbes.com/sites/patsydoerr/2018/10/23/ changing-the-status-quo-how-women-are-leading-the-charge-on-impactinvesting/\#5fe92cab5bbe. Accessed 2 Sept 2019

Druckman JN, Kam CD (2011) Students as experimental participants. Camb Handb Exp Political Sci 1:41-57

Emerson J, Norcott L (2016) Millennials will bring impact investing mainstream Epstein MJ, Yuthas K (2017) Measuring and improving social impacts: a guide for nonprofits, companies and impact investors. Routledge

Esteves AM, Franks D, Vanclay F (2012) Social impact assessment: the state of the art. Impact Assess Proj Appraisal 30:34-42

Ficher MS (2017) Women are savvier investors than they think. https://www thinkadvisor.com/2017/05/18/women-are-savvier-investors-than-they-think/ ?slreturn=20190806061128. Accessed 2 Sept 2019

Findler F (2019) Scoping what matters: an introduction to impact mapping. In: Schönherr N, Martinuzzi A (eds), Business and the sustainable development goals. Springer International Publishing, pp. 55-74

Financial Times (2018). The younger generation needs better advice on impact investing. https://www.ft.com/content/bebd2b92-605c-11e9-9300-0becfc937c37. Accessed 27 Apr 2020

Floyd D (2019) What a relief! a review of social investment tax relief for charities and social enterprises. https://www.sibgroup.org.uk/sites/default/files/files/ What\%20A\%20Relief\%20-\%20SITR\%20research\%20report.pdf. Accessed 2 Sept 2019

GECES (2016) Social enterprises and social economy going forward. https://ec. europa.eu/growth/content/social-enterprises-and-social-economy-goingforward-0_en. Accessed 2 Sept 2019

GIIN (2016) Impact investing trends evidence of a growing industry. https://thegiin. org/research/publication/impact-investing-trends. Accessed 2 Sept 2019

GIIN (2019) Annual impact investor survey. https://thegiin.org/research/ publication/annualsurvey2018. Accessed 2 Sept 2019

Gneezy U, Keenan EA, Gneezy A (2014) Avoiding overhead aversion in charity. Science 346:632-635

Gunstone B, Gavin E (2017) Insights into charity fundraising. https://www. institute-of-fundraising.org.uk/library/insights-into-charity-fundraisingfinal-report/. Accessed 2 Sept 2019

Hervieux C, Voltan A (2019) Toward a systems approach to social impact assessment. Soc Enterp J 15:264-286

HMRC (2018) Enterprise investment scheme, seed enterprise investment scheme and social investment tax relief-statistics on companies raising funds. https://www.gov.uk/government/statistics/enterprise-investment-scheme- 
seed-enterprise-investment-scheme-and-social-investment-tax-reliefstatistics-may-2018. Accessed 2 Sept 2019

Jackson ET (2013) Evaluating social impact bonds: questions, challenges, innovations, and possibilities in measuring outcomes in impact investing. Community Dev 44:608-616

Karytsas S, Mendrinos D, Karytsas M (2013) Measurement methods of socioeconomic impacts of renewable energy projects IOP Conf Ser: Earth Environ Sci 410:012087. https://doi.org/10.1088/1755-1315/410/1/012087

Lee MDP (2008) A review of the theories of corporate social responsibility: its evolutionary path and the road ahead. Int J Manag Rev 10:53-73

Lewis A (2002) Morals markets and money: ethical, green and socially responsible investing. Prentice Hall, Harlow

Maciel Cardoso F (2019) Data and SI for: understanding drivers when investing for impact. https://doi.org/10.7910/DVN/G5ONIF

MBA D (2017) Three things: what is impact investing? https://www.youtube.com/ watch? $\mathrm{v}=$ WBNAsvlnERs. Accessed 2 Sept 2019

McWilliams A, Siegel D (2000) Corporate social responsibility and financial performance: correlation or misspecification? Strateg Manag J 21:603-609

Molina JA, Ferrer A, Giménez-Nadal JI, Gracia-Lázaro C, Moreno Y, Sánchez A (2019) Intergenerational cooperation within the household: a public good game with three generations. Rev Econ Househ 17:535-552

Novak PK, De Amicis L, Mozetič I (2018) Impact investing market on twitter: influential users and communities. Appl Netw Sci 3:40

O’Connor C, Labowitz S (2017) Measuring human rights performance for Investors. Technical Report March. NYU Stern Center for Business and Human Rights. http://bhr.stern.nyu.edu

Portales L (2019) Social impact in social innovations: definition, design, and evaluation. In: Portales L (ed), Social innovation and social entrepreneurship. Springer International Publishing, pp. 161-176

Serafeim G, Trinh K, Zochowski RA (2020). Preliminary framework for product impact-weighted accounts. SSRN Electron J https://doi.org/10.2139/ ssrn. 3532472

Stanley M (2014) Morgan Stanley private wealth management \& campden wealth. http://www.campdenresearch.com/content/next-generation-wealth-report Accessed 2 Sept 2019

Stecker MJ (2014) Revolutionizing the nonprofit sector through social entrepreneurship. J Econ Issues 48:349-358

Tsotsotso K (2020) Is programme evaluation the same as social impact measurement? J Soc Entrep https://doi.org/10.1080/19420676.2019.1683877
Wiepking P, Bekkers R (2012) Who gives? a literature review of predictors of charitable giving. part two: gender, family composition and income. Volunt Sect Rev 3:217-245

Wins A, Zwergel B (2015) Private ethical fund investors across countries and time: a survey-based review. Qual Res Financ Mark 7:379-411

\section{Competing interests}

The authors declare no competing interests.

\section{Additional information}

Supplementary information is available for this paper at https://doi.org/10.1057/s41599020-0447-y.

Correspondence and requests for materials should be addressed to F.M.C.

Reprints and permission information is available at http://www.nature.com/reprints

Publisher's note Springer Nature remains neutral with regard to jurisdictional claims in published maps and institutional affiliations.

\section{(c) (i)}

Open Access This article is licensed under a Creative Commons Attribution 4.0 International License, which permits use, sharing, adaptation, distribution and reproduction in any medium or format, as long as you give appropriate credit to the original author(s) and the source, provide a link to the Creative Commons license, and indicate if changes were made. The images or other third party material in this article are included in the article's Creative Commons license, unless indicated otherwise in a credit line to the material. If material is not included in the article's Creative Commons license and your intended use is not permitted by statutory regulation or exceeds the permitted use, you will need to obtain permission directly from the copyright holder. To view a copy of this license, visit http://creativecommons.org/ licenses/by/4.0/

(C) The Author(s) 2020 